\title{
Gene-environment interaction: a central concept in multifactorial diseases
}

\author{
Laurence Tiret \\ Institut National de la Santé et de la Recherche Médicale (INSERM) U525, Faculté de Médecine Pitié-Salpétrière, 91 Bd de \\ l'Hôpital, 75634 Paris Cedex, France
}

\begin{abstract}
Unlike the rare and severe genetic defects that cause monogenic diseases, the genetic factors that modulate the individual susceptibility to multifactorial diseases (cardiovascular diseases, cancers, diabetes, etc.) are common, functionally different, forms of genes (polymorphisms), which generally have a modest effect at an individual level but, because of their high frequency in the population, can be associated with a high attributable risk. Environmental factors can reveal or facilitate the phenotypic expression of such susceptibility genes. Indeed, in common diseases genetic effects can be considerably amplified in the presence of triggering factors. There is now accumulating evidence that most of the susceptibility genes for common diseases do not have a primary aetiological role in predisposition to disease, but rather act as response modifiers to exogenous factors such as stress, environment, disease, drug intake. A better characterisation of the interactions between environmental and genetic factors constitute a key issue in the understanding of the pathogenesis of multifactorial diseases. The present paper will review three examples of gene-environment interactions in the field of CHD.
\end{abstract}

\section{Résumé}

A la différence des mutations génétiques rares mais sévères qui causent les maladies monogéniques, les facteurs génétiques qui modulent la susceptibilité individuelle aux maladies multifactorielles (maladies cardiovasculaires, cancer, diabète) sont des formes fréquentes, fonctionnellement différentes, des gènes (polymorphismes) qui ont généralement un effet modeste au niveau individuel, mais en raison de leur grande fréquence dans la population, peuvent être associés à un risque attribuable élevé. Les facteurs environnementaux peuvent révéler ou faciliter l'expression phénotypique de ces gènes de susceptibilité. En effet, dans le cas des maladies communes, les effets génétiques peuvent être considérablement amplifiés en présence de facteurs déclenchants. On sait maintenant que la plupart des gènes de susceptibilité aux maladies communes n'ont pas un rôle étiologique primaire dans la prédisposition à la maladie mais agissent plutôt comme des modificateurs dans la réponse à des facteurs exogènes tels que le stress, l'environnement, la maladie, la prise de médicament, le régime alimentaire. Une meilleure caractérisation des interactions entre facteurs génétiques et environnementaux constitue un élément clé dans la compréhension de la pathogénèse des maladies multifactorielles. Cet article présente trois exemples d'interaction gène-environnement dans le domaine des maladies coronariennes.

\section{Gene-environmment interaction: Common diseases}

Unlike the rare and severe genetic defects that cause monogenic diseases, the genetic factors that modulate the individual susceptibility to multifactorial diseases (cardiovascular diseases, cancers, diabetes, etc.) are common, functionally different, forms of genes (polymorphisms), which generally have a modest effect at an individual level but, because of their high frequency in the population, can be associated with a high attributable risk. Environmental

\footnotetext{
Abbreviations: BP, blood pressure; CETP, cholesteryl ester transfer protein; EARS, European Atherosclerosis Research Study; ET-1, endothelin-1; LPL, lipoprotein lipase; MI, myocardial infarction; MONICA, Monitoring in Cardiovascular Diseases.

*Corresponding author: Dr Laurence Tiret, fax +331407797 28, email tiret@idf.inserm.fr
} 
factors can reveal or facilitate the phenotypic expression of susceptibility genes, either because a genetic polymorphism affects metabolic pathways, which depend on the presence of substrates provided by the environment, or because expression of a gene induced by an environmental factor (drug, diet, smoking, etc.) is modified by a polymorphism. A better characterisation of the interactions between environmental and genetic factors constitutes a key issue in the understanding of the pathogenesis of multifactorial diseases. The present paper will review three examples of gene-environment interactions in the field of CHD.

\section{Cholesteryl ester transfer protein gene, alcohol consumption, HDL-cholesterol and myocardial infarction}

A high plasma level of HDL-cholesterol is a strong protective factor against CHD (Gordon \& Rifkind, 1989). Cholesteryl ester transfer protein (CETP) plays a key role in HDL metabolism by promoting the transfer of cholesteryl esters from the core of HDL particles to triacylglycerol-rich lipoproteins, in exchange for triacylglycerols (Tall, 1993). An increased CETP activity, by reducing the cholesterol content of HDL, may thus contribute to an increased risk of CHD. On the other hand, moderate alcohol consumption has consistently been shown in epidemiological studies to be a protective factor against CHD. This association is largely mediated by the effect of alcohol on HDL-cholesterol, which is itself partly due to the effect of alcohol on CETP activity (Tall, 1993). It was tempting, therefore, to speculate that genetic variations in the CETP gene might be involved in the relationship between alcohol, HDL-cholesterol and CHD.

This hypothesis was investigated in the Etude CasTémoin sur l'Infarctus du Myocarde Study, a case-control study on myocardial infarction (MI) performed in two populations, Northern Ireland and France, having contrasting incidences of CHD (Fumeron et al. 1995). Cases (n 650) were male patients with MI recruited from World Health Organization (Monitoring in Cardiovascular Diseases; MONICA) registers. Population-based control groups ( $n$ 750) were randomly sampled from the populations covered by the registers. A frequent polymorphism of the CETP gene located in intron 1 (CETP/Taq1B), which had been previously shown to be associated with HDL-cholesterol in several studies, was genotyped in all study participants.

The CETP/Taq1B polymorphism was strongly associated with CETP mass and HDL-related variables in a codominant fashion (Fig. 1). Although alcohol consumption did not modify the relationship between genotype and CETP mass, there was a strong interaction between alcohol and genotype on HDL-cholesterol levels (Fig. 2). Actually, the genotype effect on HDL-cholesterol was absent in teetotallers, whereas it increased progressively with increasing consumption in alcohol drinkers. A similar interaction was observed with other HDL-related variables.

The increased levels of HDL-cholesterol associated with the CETP/B2 allele in alcohol drinkers suggested that presence of this allele might be protective against CHD in this subgroup. The results shown in Fig. 3 are compatible (a)

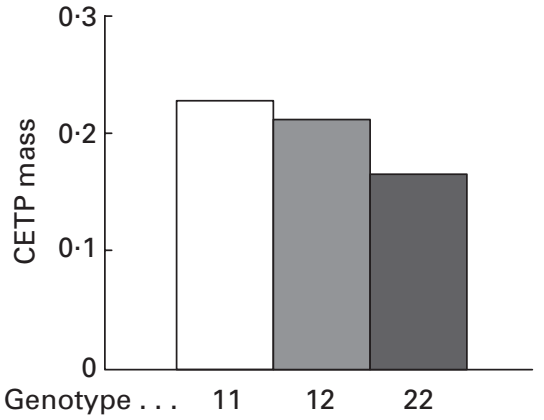

(d)

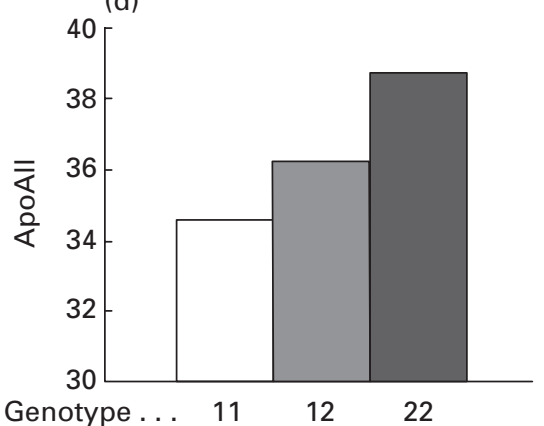

(b)

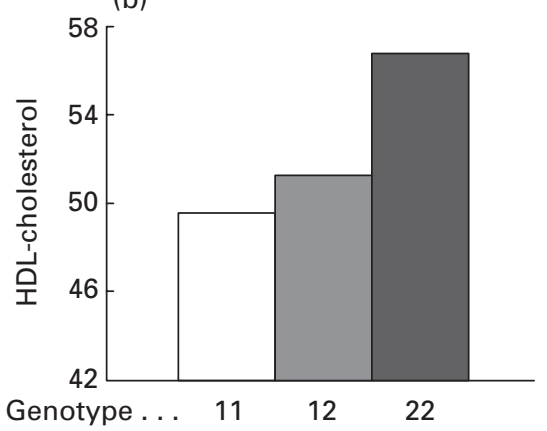

(e)

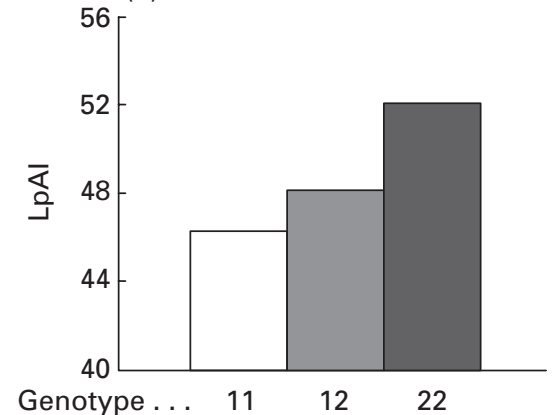

(c)

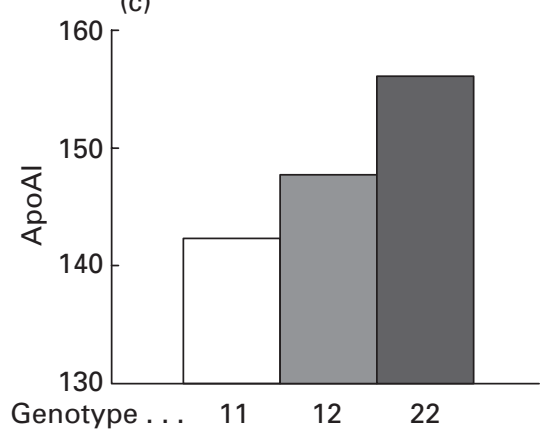

(f)

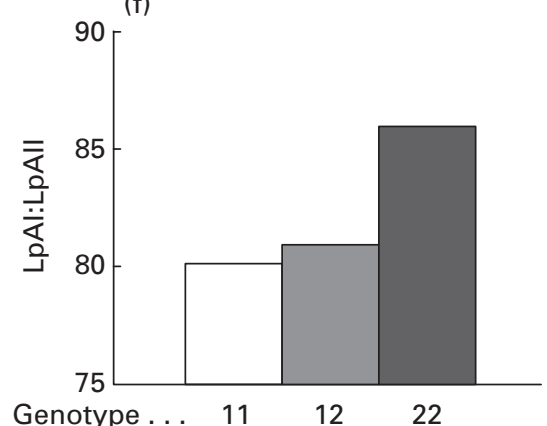

Fig. 1. Effect of the cholesteryl ester transfer protein (CETP/Taq1B) polymorphism on CETP mass (a) and lipid-related variables (b-f) in the Etude Cas-Témoin sur l'Infarctus du Myocarde Study. ApoAI, ApoAll, apoproteins A-I and A-II respectively; LpAI, LpAll, lipoproteins A-I and A-Il respectively. (From Fumeron et al. 1995.) 


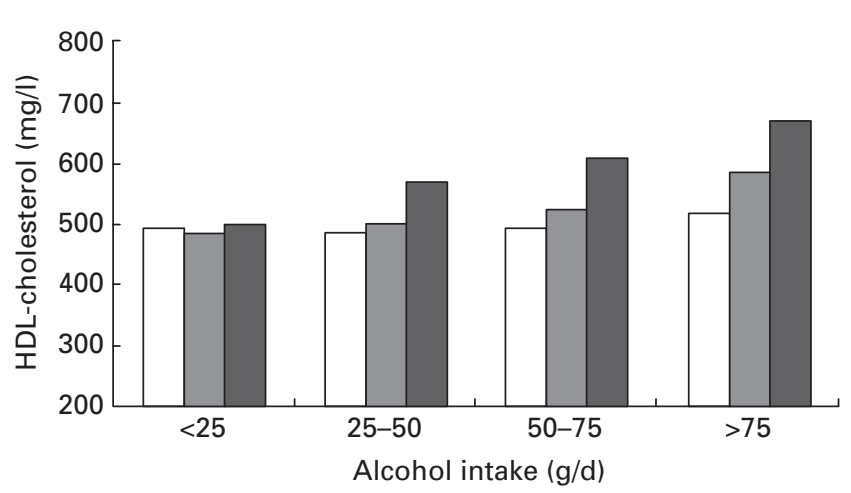

Fig. 2. Effect of the cholesteryl ester transfer protein (CETP)/Taq1B polymorphism on HDL-cholesterol according to alcohol consumption in the Etude Cas-Témoin sur l'Infarctus du Myocarde Study. $(\square)$, Genotype 11; (ख), genotype 12, (回), genotype 22. The genotype $\times$ alcohol interaction was significant $(P<0 \cdot 0001)$. (From Fumeron et al. 1995.)

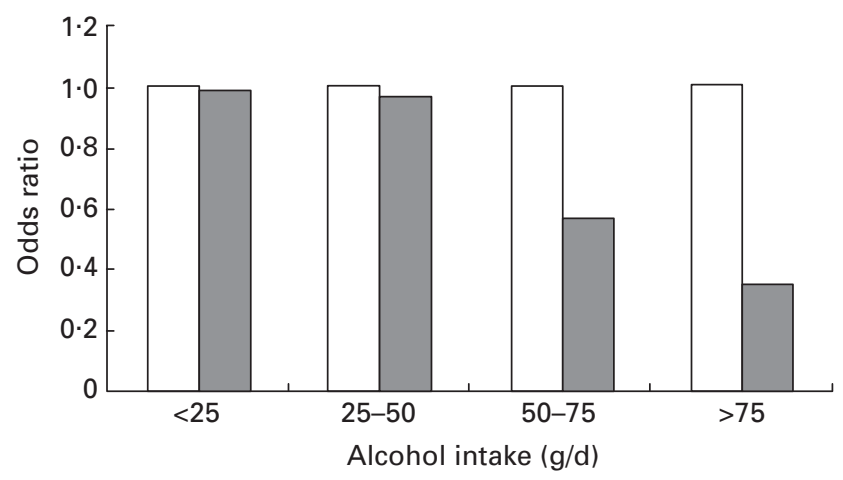

Fig. 3. Effect of the cholesteryl ester transfer protein (CETP)/Taq1B polymorphism on the risk of myocardial infarction according to alcohol consumption in the Etude Cas-Témoin sur l'Infarctus du Myocarde Study. ( $\square$ ), Genotypes 11 and 12; ( genotype $\times$ alcohol interaction was significant $(P<0 \cdot 05)$. (From Fumeron et al. 1995.)

with this hypothesis. In alcohol drinkers, subjects homozygous for the B2 allele had a lower risk of MI than $\mathrm{B} 1 \mathrm{~B} 1$ or B1B2 subjects, as attested by an odds ratio of $<1$. This odds ratio markedly decreased with increasing alcohol consumption, so that in the highest category of alcohol intake, the risk of MI was divided by 3 in B2B2 homozygotes. This interaction between alcohol intake and genotype was observed in populations of both Northern Ireland and France.

These results provided the first demonstration of a geneenvironment interaction affecting both the susceptibility to CHD and an intermediate phenotype such as HDLcholesterol (Fumeron et al. 1995). However, the CETP/ Taq1B polymorphism, as mentioned earlier, is located in an intron and is unlikely to be functional by itself, but is rather a neutral marker of a functional polymorphism unidentified at the time of this first study. These results motivated us to perform an exhaustive molecular screening of the CETP gene in order to identify all frequent polymorphisms of the coding and regulatory regions (Corbex et al. 2000). Several polymorphisms were detected, among which one was located in the promoter region (CETP/C-629A) and was in nearly complete association with the Taq1B marker. This polymorphism was further shown to be functional; the A allele, which is in complete association with the 'protective' B2 allele, exhibiting a decreased CETP gene expression in in vitro experiments (Dachet et al. 2000). This polymorphism was then responsible for the effects observed with the Taq1B marker. However, an extensive association analysis of all polymorphisms identified revealed that the genotype-phenotype relationship was more complex than initially thought, and that there were probably several functional variants within the CETP gene affecting CETP mass, HDL-cholesterol levels and CHD risk (Corbex et al. 2000).

Interestingly, a recent clinical trial suggested that the CETP/Taq1B polymorphism interacted with statin therapy to modulate the progression of coronary atherosclerosis in CHD patients (Kuivenhoven et al. 1998). The B2 allele was associated with a significant reduction in the progression of atherosclerosis in the placebo group $(P<0 \cdot 05)$, confirming the protective effect associated with this allele. However, this protective effect was abolished by statin therapy. This interaction could also be interpreted in a symmetrical way, indicating that only B1B1 subjects would be expected to benefit from statin therapy (Kuivenhoven et al. 1998).

\section{Endothelin-1 gene polymorphism, BMI and blood pressure}

Endothelin-1 (ET-1) is a powerful vasoconstrictor peptide produced by endothelial and smooth muscle cells. It is found in a variety of tissues where it acts as a modulator of vasomotor tone, cell proliferation and hormone production (Levin, 1995). There is accumulating evidence from experimental and clinical data that ET-1 plays an important role in the pathophysiology of the vascular system, and more specifically in the hypertensive process. Supporting this concept, long-term treatment by an endothelin-receptor antagonist in hypertensive patients results in a significant reduction in blood pressure (BP; Krum et al. 1998).

We investigated in the Etude Cas-Témoin sur l'Infarctus du Myocarde Study whether molecular variations at the ET-1 locus might be involved in the predisposition to MI and the determination of BP levels (Tiret et al. 1999). The coding and regulatory sequences of the ET-1 gene were screened for identification of frequent polymorphisms. Five polymorphisms were detected, among which one predicts an amino acid change at codon 198 (ET-1/Lys198Asn). The frequency of the Asn 198 allele was $0 \cdot 26$ in Northern Ireland and 0.22 in France, and did not differ between MI patients and control subjects in either population. The ET-1/ Lys198Asn polymorphism did not affect BP levels in the population at large. However, it strongly interacted with BMI in the determination of both systolic and diastolic BP. The interaction reflected a steeper increase in BP levels with BMI in subjects carrying the Asn198 allele than in subjects homozygous for the Lys 198 allele (Fig. 4). As a consequence of this interaction, the effect of the Asn 198 allele on BP levels appeared reversed between lower and higher BMI values (Fig. 5). 
To determine whether the findings observed in the Etude Cas-Témoin sur l'Infarctus du Myocarde Study could be replicated in an independent study, the ET-1/Lys198Asn polymorphism was genotyped in the Glasgow Heart Scan Study (McDonagh et al. 1997). This large cross-sectional study was based on samples randomly selected from a geographic area covered by the Glasgow MONICA register. In this study, a large percentage of subjects (68) performed a treadmill exercise test during which BP was measured. The maximum BP achieved during exercise was significantly higher in homozygotes for the Asn 198 allele $(P<0 \cdot 05)$, with heterozygotes having intermediate levels. Moreover, there was a significant interaction between BMI and genotype on maximum BP $(P<0 \cdot 001)$. Again, this interaction reflected a steeper increase of maximum BP with BMI in carriers of the Asn198 allele (Fig. 6).

In summary, results from two independent studies suggest that obesity is a crucial factor influencing the association between the ET-1/Lys198Asn polymorphism and BP levels. Several lines of evidence suggest that obesity might be a factor that enhances the expression of the ET-1 gene, possibly through an up-regulation by insulin, which is known to stimulate ET-1 production (Ferri et al. 1995).

\section{Lipoprotein lipase gene, fat challenge and postprandial triacylglycerol levels}

Lipoprotein lipase (LPL) plays a key role in the metabolism of the triacylglycerol-rich lipoproteins, by hydrolysing triacylglycerols in chylomicrons and VLDL. Elevated fasting triacylglycerols levels are associated with an increased risk of atherosclerosis and CHD independently of other lipids. Fasting levels of lipids and lipoproteins, however, only partially reflect the complex link between dyslipoproteinaemia and atherosclerosis. Following the hypothesis formulated 20 years ago by Zilversmit (1979), there is now accumulating evidence that postprandial lipaemia plays an important role in the atherogenic process and its complications (Karpe, 1999). Since postprandial lipaemia is largely determined by LPL, the LPL gene constitutes an obvious candidate gene potentially influencing the response to a fat challenge.

We investigated this hypothesis in the European Atherosclerosis Research Study (EARS). This study was designed to investigate the biological expression of a paternal history of premature CHD in young individuals (European Atherosclerosis Research Study Group, 1994). It was based on the comparison of offspring whose father had suffered an MI before the age of 55 years with appropriate control subjects in fourteen different populations of Europe.

Following the first results of the EARS, indicating that an altered fasting profile of atherogenic lipoproteins constituted a major biological expression of a family history of premature CHD (Rosseneu et al. 1994), the EARS II was undertaken to investigate whether these results might be partly explained by an alteration in postprandial lipaemia. Cases with a paternal history of MI $(n 407)$ and age-matched controls $(n$ 415) all received a standard-fat meal administered in the morning after a $12 \mathrm{~h}$ overnight fast, and triacylglycerolaemia was measured at $0,2,3,4$ and $6 \mathrm{~h}$. Two non-synonymous polymorphisms of the LPL gene were

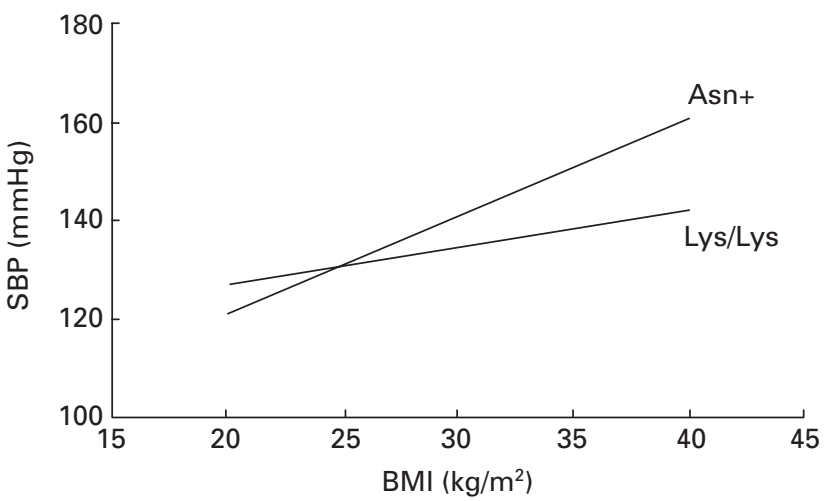

Fig. 4. Regression slopes of systolic blood pressure (SBP) on BMI according to the endothelin-1/Lys198Asn polymorphism in the Etude Cas-Témoin sur l'Infarctus du Myocarde Study. Asn+, subjects carrying the Asn198 allele; Lys/Lys, subjects homozygous for Lys198 allele. The genotype $\times \mathrm{BMI}$ interaction was significant $(P<0.001)$. (From Tiret et al. 1999.)

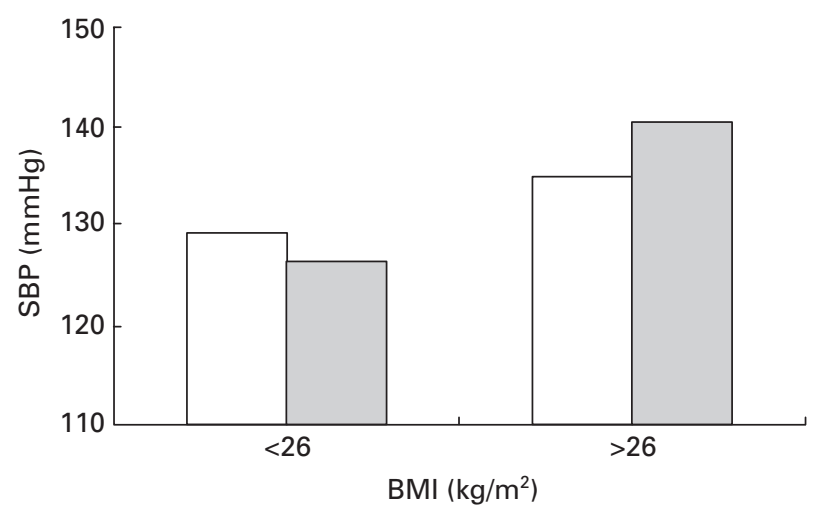

Fig. 5. Effect of the endothelin-1/Lys198Asn polymorphism on systolic blood pressure (SBP) according to level of BMI in the Etude Cas-Témoin sur I'Infarctus du Myocarde Study. $(\square)$, Subjects homozygous for Lys198 allele; ( allele. For $\mathrm{BMI}<26 \mathrm{~kg} / \mathrm{m}^{2}$ the difference between the groups was not significant $(P=0 \cdot 15)$; for $\mathrm{BMI}>26 \mathrm{~kg} / \mathrm{m}^{2}$ the difference between the groups was significant $(P=0 \cdot 009)$. (From Tiret et al. 1999.)

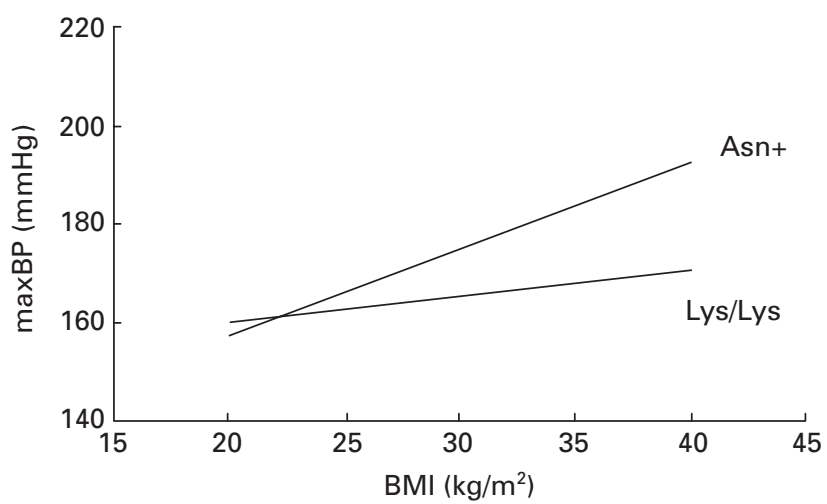

Fig. 6. Regression slopes of maximum blood pressure (maxBP) achieved during treadmill exercise test on BMI according to the endothelin-1/Lys198Asn polymorphism in the Glasgow Heart Scan study. Asn+, subjects carrying the Asn198 allele, Lys/Lys, subjects homozygous for Lys 198 allele. The genotype $\times \mathrm{BMI}$ interaction was significant $(P<0 \cdot 001)$. (From Tiret et al. 1999.) 
genotyped; the common LPL/Ser447Stop polymorphism resulting in a premature truncation of the enzyme and associated with higher expression in in vitro studies (Humphries et al. 1998), and the less common LPL/Asn291Ser variant (Gerdes et al. 1997).

As shown in Fig. 7, the LPL/Stop447 allele frequency was lower in the cases than in the controls. It was also associated with a significant decrease in fasting triacylglycerol levels $(P<0.01)$, which paralleled the decrease in the odds ratio of having a paternal history of MI. Interestingly, this 'protective' allele was more frequent in populations from the South of Europe, which have a lower incidence of CHD. The LPL/Stop447 allele was also associated with a significantly lower postprandial triacylglycerolaemia $(P<0.02$; Fig. 8). These results are consistent with a role of the LPL/Ser447Stop polymorphism influencing both fasting and postprandial triacylglycerols levels and mediating the familial risk of CHD.

Unlike the LPL/Ser447Stop polymorphism, the LPL/Asn291Ser polymorphism did not differ in frequency between cases and controls, nor did it significantly affect fasting triacylglycerol levels. Carriers of the rare LPL/Ser291 allele, however, had significantly lower fasting HDL-cholesterol levels $(P<0 \cdot 05)$. The LPL/Ser291 allele was associated with an increased postprandial response, and this effect tended to be more pronounced in the cases than in the controls, although the test of heterogeneity did not reach statistical significance because of the small numbers of carriers of the LPL/Ser291 allele (Fig. 9). The activity of the LPL/Ser291 mutation has been shown to be reduced by $30-40 \%$ in in vitro experiments and, therefore, carriers of this allele might have a less efficient postprandial clearance of triacylglycerol-rich lipoproteins. The fact that individuals with a familial history of CHD exhibited a more pronounced response than controls suggests that this variant might interact with other genetic or environmental factors that amplify the response of cases.

In summary, results from the EARS suggest that polymorphisms of the LPL gene constitute genetic risk factors for CHD whose expression is already discernible in young (a)

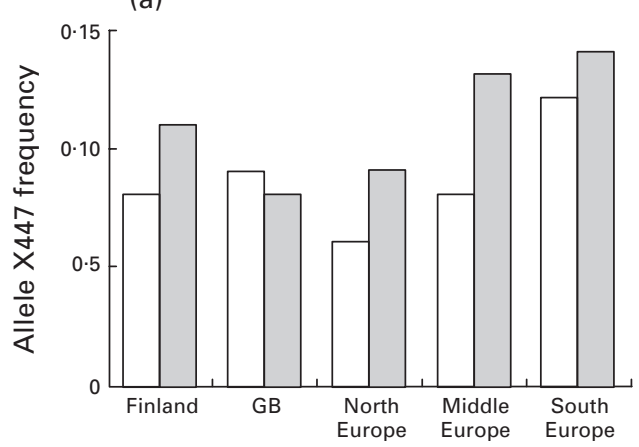

(b)

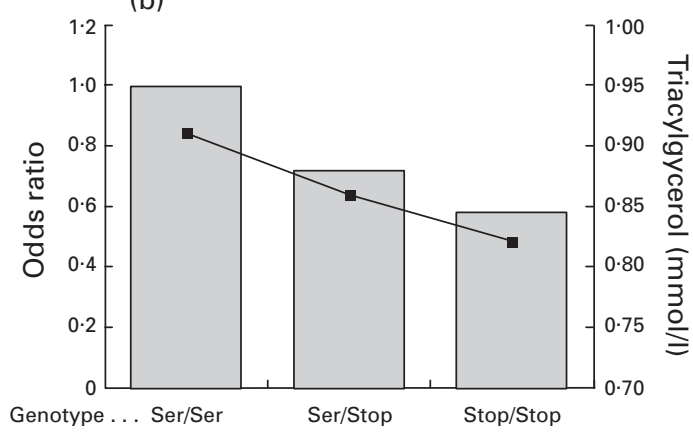

Fig. 7. Allele frequency of the lipoprotein lipase/Ser447Stop polymorphism (a) and the effect on fasting triacylglycerols (b) in the European Atherosclerosis Research Study in which patients with a paternal history of myocardial infarction and age-matched controls were fed a standard-fat meal in the morning after a $12 \mathrm{~h}$ fast. GB, Great Britain. $\square$ ), Cases; ( significant $(P=0.008$ and $P=0.007$ respectively). ( Humphries et al. 1998.)

(a) Cases

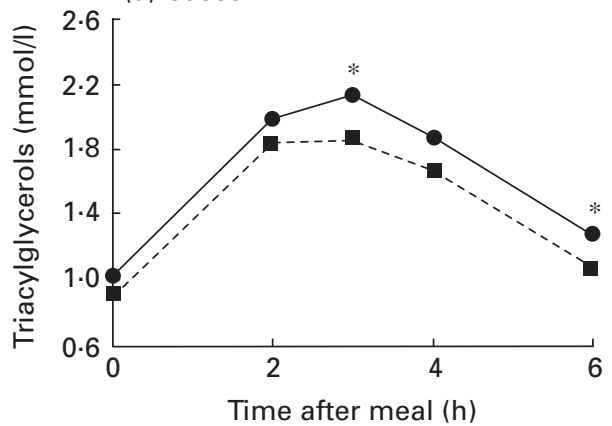

(b) Controls

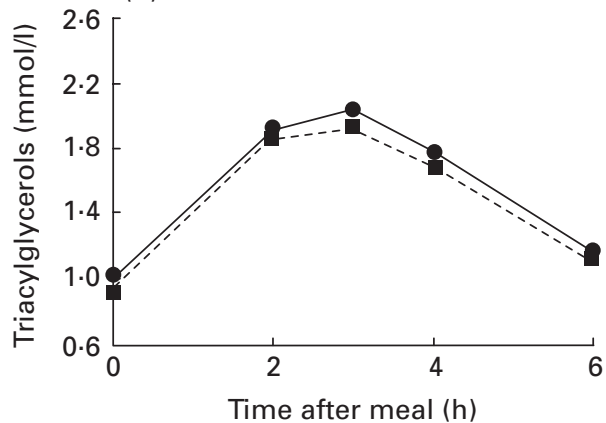

Fig. 8. Postprandial changes in triacylglycerols concentrations according to the lipoprotein lipase/Ser447Stop polymorphism in the European Atherosclerosis Research Study in which patients with a paternal history of myocardial infarction (a) and age-matched controls (b) were fed a standard-fat meal

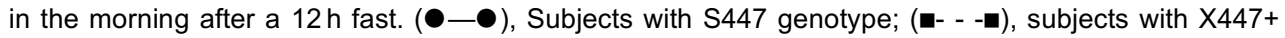
genotype. Mean value for cases with the $\$ 447$ genotype was significantly different from that for cases with the $X 447+$ genotype: ${ }^{*} P<0 \cdot 05$. The postprandial response in the subjects with the $X 447+$ genotype was significantly lower than that of subjects with the $\$ 447$ genotype $(P<0 \cdot 02)$. There was no significant case-control heterogeneity. (From Humphries et al. 1998.) 
(a) Cases

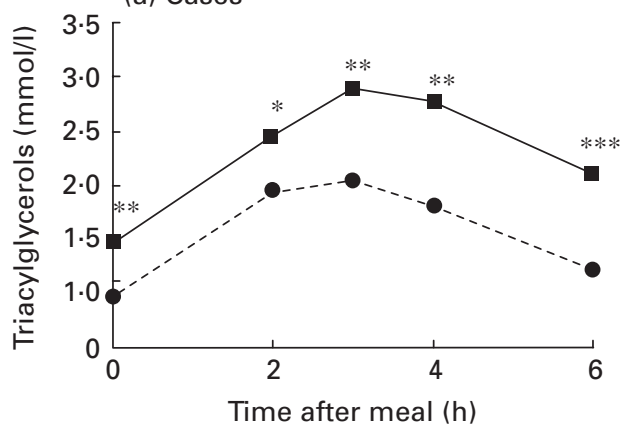

(b) Controls

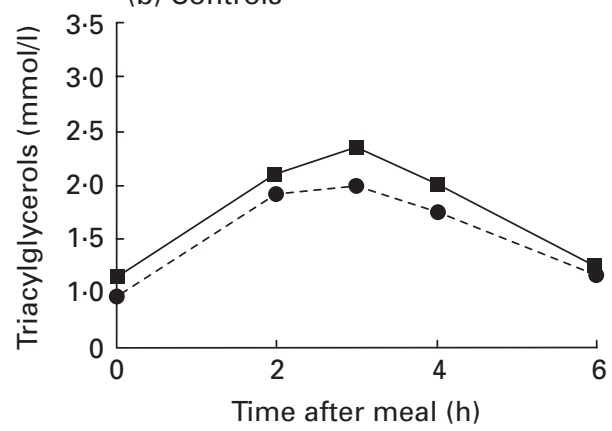

Fig. 9. Postprandial changes in triacylglycerol concentrations according to the lipoprotein lipase/Asn291Ser polymorphism in the European Atherosclerosis Research Study in which patients with a paternal history of myocardial infarction (a) and age-matched controls (b) were fed a standard-fat meal in the morning after a $12 \mathrm{~h}$ fast. ( $\mathbf{\square - \square})$, subjects with SL91+ genotype; $(\mathbf{- \bullet})$, subjects with N291 genotype. Mean values for cases with $\mathrm{S} 291+$ genotype were significantly different from those for cases with the N291 genotype: ${ }^{*} P<0.05,{ }^{* *} P<0.01,{ }^{* * *} P<0.001$. The postprandial response in the cases with the S291+ genotype was significantly higher than that of those with the N291 genotype $(P<0 \cdot 05)$. There was no significant case-control heterogeneity. (From Gerdes et al. 1997.)

healthy individuals. These effects might be amplified later in life due to the action of other genetic or lifestyle risk factors, as attested by the stronger effect already observed in young individuals with a familial risk profile.

\section{Conclusion}

These few examples illustrate how lifestyle and genetic factors are intimately related in the aetiology of multifactorial diseases. Indeed, in common diseases genetic effects are generally modest, but can be considerably amplified in the presence of triggering factors. There is now accumulating evidence that most of the susceptibility genes to common diseases do not have a primary aetiological role in the predisposition to disease, but rather act as response modifiers to exogenous factors such as stress, environment, disease, drug intake. This finding implies that lifestyle factors should be thoroughly investigated in genetic studies of multifactorial diseases, and conversely that genetic factors should be more systematically assessed in clinical trials and diet interventions.

\section{References}

Corbex M, Poirier O, Fumeron F, Betoulle D, Evans A, Ruidavets JB, Arveiler D, Luc G, Tiret L \& Cambien F (2000) Extensive association analysis between the CETP gene and coronary heart disease phenotypes reveals several putative functional polymorphisms and gene-environment interaction. Genetic Epidemiology 19, 64-80.

Dachet C, Poirier O, Cambien F, Chapman J \& Rouis M (2000) New functional promoter polymorphism, CETP/-629, in cholesteryl ester transfer protein (CETP) gene related to CETP mass and high density lipoprotein cholesterol levels: role of $\mathrm{Sp} 1 / \mathrm{Sp} 3$ in transcriptional regulation. Arteriosclerosis, Thrombosis and Vascular Biology 20, 507-515.

European Atherosclerosis Research Study Group (1994) The European Atherosclerosis Research Study: design and objectives. International Journal of Epidemiology 23, 465-471.
Ferri C, Pittoni V, Piccoli A, Laurenti O, Cassone MR, Bellini C, Properzi G, Valesini G, De Mattia G \& Santucci A (1995) Insulin stimulates endothelin-1 secretion from human endothelial cells and modulates its circulating levels in vivo. Journal of Clinical Endocrinology and Metabolism 80, 829-835.

Fumeron F, Betoulle D, Luc G, Behague I, Ricard S, Poirier O, Jemaa R, Evans A, Arveiler D, Marques-Vidal P, Bard JM, Fruchart JC, Ducimetière P, Apfelbaum M \& Cambien F (1995) Alcohol intake modulates the effect of a polymorphism of the cholesteryl ester transfer protein gene on plasma high density lipoprotein and the risk of myocardial infarction. Journal of Clinical Investigation 96, 1664-1671.

Gerdes C, Fisher RM, Nicaud V, Boer J, Humphries SE, Talmud PJ \& Faergeman O (1997) Lipoprotein lipase variants D9N and N291S are associated with increased plasma triglyceride and lower high-density lipoprotein cholesterol concentrations Studies in the fasting and postprandial states: The European Atherosclerosis Research Studies. Circulation 96, 733-740.

Gordon DJ \& Rifkind BM (1989) HDL - the clinical implications of recent studies. New England Journal of Medicine 321, 1311-1316.

Humphries SE, Nicaud V, Margalef J, Tiret L \& Talmud PJ (1998) Lipoprotein lipase gene variation is associated with paternal history of premature coronary artery disease and fasting and post-prandial plasma triglycerides: European Atherosclerosis Research Study. Arteriosclerosis, Thrombosis and Vascular Biology 18, 526-534.

Karpe F (1999) Postprandial lipoprotein metabolism and atherosclerosis. Journal of Internal Medicine 246, 341-355.

Krum H, Viskoper RJ, Lacourciere Y, Budde M \& Charlon V (1998) The effect of an endothelin-receptor antagonist, bosentan, on blood pressure in patients with essential hypertension. Bosentan Hypertension Investigators. New England Journal of Medicine 338, 784-790.

Kuivenhoven JA, Jukema JW, Zwinderman AH, de Knijff P, McPherson R, Bruschke AV, Lie KI \& Kastelein JJ (1998) The role of a common variant of the cholesteryl ester transfer protein gene in the progression of coronary atherosclerosis. The Regression Growth Evaluation Statin Study Group. New England Journal of Medicine 338, 86-93.

Levin ER (1995) Endothelins. New England Journal of Medicine 333, 356-363. 
McDonagh TA, Morrison CE, Lawrence A, Ford I, Tunstall-Pedoe H, McMurray JJ \& Dargie HJ (1997) Symptomatic and asymptomatic left-ventricular systolic dysfunction in an urban population. Lancet 350, 829-833.

Rosseneu M, Fruchart JC, Bard JM, Nicaud V, Vinaimont N, Cambien F \& De Baker G (1994) Plasma apolipoprotein concentrations in young adults with a parental history of premature coronary heart disease and in control subjects. The EARS Study. Circulation 89, 1967-1973.
Tall AR (1993) Plasma cholesteryl ester transfer protein. Journal of Lipid Research 34, 1255-1274.

Tiret L, Poirier O, Hallet V, McDonagh T, Morrison C, McMurray J, Dargie H, Arveiler D, Ruidavets J, Luc G, Evans A \& Cambien F (1999) The Lys198Asn polymorphism in the endothelin-1 gene is associated with blood pressure in overweight people. Hypertension 33, 1169-1174.

Zilversmit DB (1979) Atherogenesis: a postprandial phenomenon. Circulation 3, 473-485. 